\title{
Social cohesion in rural Australia: framework for conformity or social justice?
}

Authors:

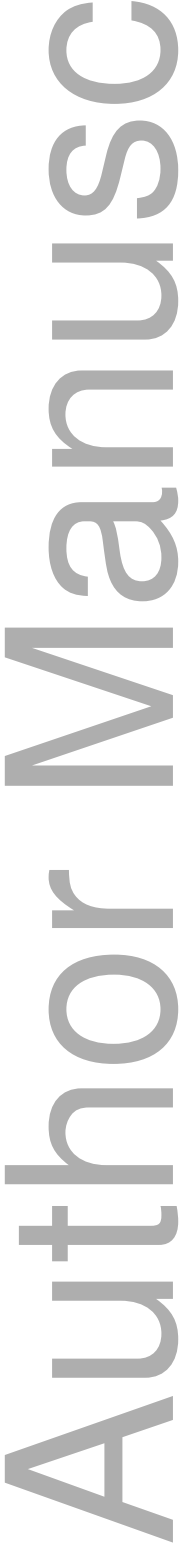

This is the author manuscript accepted for publication and has undergone full peer review but has not been through the copyediting, typesetting, pagination and proofreading process, which may lead to differences between this version and the Version of Record. Please cite this article as doi: $10.1002 / \mathrm{AJS} 4.65$

This article is protected by copyright. All rights reserved 


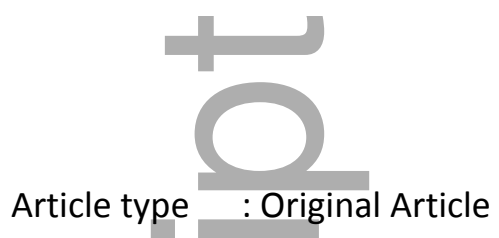

Social cohesion in rural Australia: framework for conformity or social justice?

\section{Abstract}

While social cohesion has become a commonly accepted policy goal and framework in many ethnically diverse societies, there is a general concern in some academic literature that it can be a form of governmentality that constructs manageable subjects and communities, represses diversity, and distracts attention from the social, political and economic production of inequalities. Drawing on ethnographic fieldwork in two rural Australian towns with ethnically diverse populations, this article engages with these criticisms of social cohesion while simultaneously asserting that social cohesion is viewed by local practitioners as a desirable objective for both strengthening intercultural community and addressing issues of social justice and inequality. We also aim to bring some needed clarity to relevant debates in the literature in distinguishing between social cohesion discourses used for normative and/or homogenising purposes versus frameworks developed in the academic literature with a concern for social justice and equality among diverse populations.

Key Words: governmentality, multiculturalism, rural community, policy discourse, , social justice 


\section{Introduction}

Social cohesion as a theoretical construct, and as a social goal, has a long history in the social sciences, which Jenson (1998) argued, gains more currency in periods of dramatic change and perceived social crisis. Critics of social cohesion as a government policy framework, and as a concern of political leaders and social commentators (including social scientists) attribute its rise in policy discourse and practice to neoliberalism (see Rose 1996; Stead 2017) and to the purported 'crisis' and widespread critique of multiculturalism related to contemporary mass migration (Joppke 2004; Cheong et al. 2007; Cowden \& Singh 2017). According to some, as policy it responds to the retraction of welfare state provision (Novy et al. 2012) and reflects neoliberal agendas by promoting entrepreneurial identities and communities (Jaffe 2006). Social cohesion in Europe is seen as responding to and replacing a 'failed' multicultural experiment. These critiques are vital to understanding relations between government and contemporary ethnically diverse populations, especially where the politics of community is aligned with neoliberal agendas and oriented to social order rather than social justice (Everingham 2001) and where there is a strong backlash against multiculturalism, as evident in the UK and other parts of Europe (Joppke 2004; Vertovec \& Wessendorf 2010). However, such critiques need qualification by recognising ways that 'social cohesion frameworks' also enable actors to proactively respond to issues confronting their communities (Beauvais \& Jenson 2002).

Drawing upon ethnographic fieldwork conducted in two rural Australian towns in 2015, we consider the impact of social cohesion discourse and practices among government and nongovernment agency workers. We show how such frameworks, while sometimes serving as conservative forms of governmentality, also enable thinking among local stakeholders and community members about the detrimental effects of social divisions created by racism and discrimination, economic inequality and deprivation, and other forms of exclusion in rural communities. Like social inclusion/exclusion discourse in Europe and Australia (Silver 2010), social cohesion frameworks are shaped by ideological contexts and can be conservative, or involve radical, republican and social democratic framings. They can potentially support neo-liberal agendas, but can also promote socio-economic equality, redistribution of resources and social justice in localised thinking and practice.

\section{Social cohesion and its critics}


Social cohesion has become a commonly accepted policy framework and goal in recent times, especially in Canada, Europe and Australia (Chan et al. 2006; Harris 2013, Ch. 2; Stead 2017). Jenson's (1998) widely cited account of 'social cohesion' is a touchstone for contemporary policy and thought on the topic. Drawn from an analysis of Canadian and international reports and policy documents from the 1990s, and sociological theory, Jenson highlighted five key dimensions of a socially cohesive society: Belonging....Isolation, Inclusion....Exclusion, Participation....Non-involvement, Recognition....Rejection, Legitimacy....Illegitimacy. These characteristics of social cohesion can be assessed on a spectrum, where societies are always in flux, becoming, for example, more inclusive or more exclusive for theirdiverse peoples.

'Belonging' implies shared values, consensus, commitment and collective identity (feeling oneself to be part of a shared community), while feelings of isolation among individuals and groups threaten social cohesion. 'Inclusion' is understood especially economically, through access to markets and employment. 'Participation' is understood in a multi-dimensional way but refers especially to political participation. 'Recognition' addresses the plurality of most modern societies, and points to the importance for social cohesion of processes that directly recognize and accept plural value systems. Feelings of acceptance, including for people from different ethnic, language, religious and other backgrounds, by the community, and recognition of one's contributions, is the opposite of feeling rejected because of one's difference. Finally, the dimension of 'Legitimacy' refers to acceptance of the mediating role of institutions in managing the inevitable differences and conflicts, including value differences and conflicts, in modern, plural, diverse societies. These institutions are diverse and multiple in a liberal-democratic state, and range from local, to intermediate and national. Social cohesion partly depends upon 'maintaining the legitimacy of those public and private institutions that act as mediators and maintain the spaces within which mediation can occur' (Jenson 1998: 16, bold in original).

As noted, social cohesion is a contested concept in the research literature (Bernard 1999). It is criticised as a form of governmentality that suppresses diversity (Stead 2017), distracting attention from social, political and economic forces that produce inequality, poverty, and conflict (Amin 2005; Cheong et al. 2007). Rose argued that 'government through community' (Rose 1996: 332, italics in original) is governmentality in the neoliberal age, replacing the language of the 'social' with new languages of community. He argued 'the community' has 
become 'a new territory for the administration of individual and collective existence, a new plane or surface upon which micro-moral relations among persons are conceptualized and administered' (Rose 1996: 331). Community had long been salient in political thought and in the social sciences, but, he argued, 'it becomes governmental...when it becomes technical' (Rose 1996: 332), wherein governments see community not only as a territory of government but also as a means of government.

Examining the new discourse of 'community cohesion' in the UK in the early 2000s, McGhee (2003: 376-377) claimed that one of its flaws, including in policy and programme approaches, was 'the relative de-emphasis of material deprivation and socio-economic marginalization...in favour of concentrating on inter-community relationships'. Green et al. (2009: 6) criticise the normative emphasis of much social cohesion discussion, pointing out that too much cohesion can 'lead to social insularity and backwardness,...economic sclerosis... or to a failure to address substantive injustices in society...'. In the Australian context, Bryson and Mowbray (2005) were critical of the Victorian Labor government's adoption of 'building community' and 'building social capital' rhetoric and policies for improving lives and dealing with social problems. They saw 'community capacity building' as 'low cost communitarian solutions' (Bryson and Mowbray 2005, 93) for governments keen to avoid costly and politically difficult macro policy solutions, like reducing socioeconomic inequality.

Harris (2013: 27) suggested that 'social cohesion' is an ambivalent project, pushing in different conservative and potentially radical directions. Australian governments have emphasised social cohesion since at least since the 1980s, including in multicultural policy since the 1970s (Author 2017), with an increased focus since the mid-2000s, especially targeted at youth (Harris 2013:31). Harris argued that, while social cohesion is steered by communitarian thinking emphasing the 'value of homogeneity, shared values and unity created at the level of civil society' (Harris 2013: 32; see also Cowden \& Singh 2017), communities are no longer bounded by place or strict ethnic identification, as social cohesion frameworks often imagine (Harris 2013: 33). Harris (2013: 35) noted social cohesion frameworks privilege peace, harmony and consensus over conflict, disagreement and debate. However, in Australia shared values promoted by social cohesion advocates are often based on dominant Anglo-Celtic cultural traditions and assumptions, implying assimilationist citizenship - it is all about 'them' (immigrants) adjusting to 'us' (natives, locals) (Harris 
2013: 33). They thus gravitate to notions of homogenous community, viewing difference and conflict as a threat, and remain reluctant to directly confront issues like racism.

While these critiques are important checks on social cohesion policy, some criticisms raised here apply more to particular government policies and programmes (including forms of community funding - see for example Stead, 2017), rather than to the vision of social cohesion outlined above by Jenson (1998). Jenson herself gave more space to conflict, contest and debate than Harris (and others) suggested is characteristic of social cohesion approaches. The issue of inequality was at least implicit in Jenson's dimensions, and some have added a sixth dimension of 'equality...inequality', following Bernard's (1999) critique of social cohesion's neglect of inequality (Jeannotte et al. 2002; Markus \& Dharmalingam 2007: 22).

Some Australian researchers draw on academic conceptualisations of social cohesion that are social justice oriented, emphasising the importance of the acceptance of plurality and directing attention to systemic discrimination and inequality. Dandy \& Pe-Pua (2013), in their government report on social cohesion in selected Australian cities, emphasised among the 'drivers' of social cohesion in multicultural Australia: 'Recognition of Aboriginal and Torres Strait Islanders cultures and history', 'Greater awareness and understanding of diversity and “difference", 'Frequent, positive intercultural contact', 'Support for culture maintenance among migrants, refugees and other cultural and/or linguistic minorities', 'Equality of access to resources', and 'active promotion of the value of diversity and pluralism at national (e.g., government policy, public institutions) and community (e.g., organisational cultures and policies) levels'. They also stressed that 'Racism and discrimination disrupt all social cohesion dimensions' (Dandy \& Pe-Pua 2013: vii-viii). Andrew Markus and the Scanlon Foundation's regular Mapping Social Cohesion Reports developed a scale of social cohesion using measures broadly based on Jenson's five dimensions, producing an important barometer of experiences of racism and discrimination for various different overseas-born groups, and emphasising the importance of reducing social inequalities in order to improve social cohesion (see Markus \& Dharmalingam 2007: Ch. 3).

These examples of empirical research that incorporate social-justice oriented conceptualisations of social cohesion are situated in an Australian national context in which governmental discussion and framing of social cohesion has been less connected to a backlash against multiculturalism than in Europe. Despite criticism, and race debates, 
Australia has retained an official multicultural policy since the 1970s. The backlash was more pronounced during the conservative Howard era of government (1996 to 2007), when there was both initial rejection, and then ambivalence about multiculturalism by Federal government, but was less evident during the Rudd and Gillard Labor governments (20072013), or the Abbott and Turnbull governments (2013-2018). Because social cohesion has been seen as a central element of the Australian multicultural agenda since the 1970s (Author 2017), relevant discourses may tend to be less homogenising in their conceptions of multicultural community.

The research literature presents a paradox of social cohesion. It can be variously employed to address or disguise inequalities. While the latter tendency to mask marginalisation can lead to an outright dismissal of 'social cohesion' as a framework, we argue that this does not distinguish between academic, sociological versus normative governmental uses of the concept and, importantly, does not lend itself to understanding of how the framework is employed by people in local contexts. Engaging with the criticisms of social cohesion discussed above, we interrogate localised understandings of social cohesion and community in multicultural contexts as people grapple with social issues and social problems, as well as their views on what they believe is going well in their towns. The focus of this article is 'social cohesion talk' among government and non-government workers in areas of education, local politics, policing and justice, health and social welfare, and migrant settlement, residing and working in two rural Victorian towns, Shepparton and Mildura. We explore the implications of these frameworks for the way local stakeholders understand what should be done to address community needs for diverse populations and make their communities better places to live.

\section{The study}

Shepparton and Mildura are middle-sized rural towns situated in Victoria, a south-eastern state of Australia. Shepparton has a town population of about 30,000, with the Shepparton Region (including smaller towns) having a resident population of 63,649 at the 2016 Census (ABS 2017a). Mildura has a town population also of about 30,000, with Mildura Region having a population of 53,878 (ABS 2017b). Each town has a long history of multiethnic migration, and more recently both experienced considerable in-migration of humanitarian/refugee migrants (Authors 2015). At the 2016 Census, 14.8\% of Shepparton's population (ABS 2017a) and 10.8\% of Mildura's population (ABS, 2017b) was born 
overseas. Both towns have a sizable Aboriginal and Torres Strait Islander population compared to other parts of Victoria $-3.4 \%$ of Shepparton's population (ABS, 2017a) and $3.8 \%$ of Mildura's population (2017b). Both are part of the Northern Irrigation Region of Victoria, and their economies are driven by horticultural and agricultural industries. Both towns are relatively disadvantaged in Victoria, according to the Australian Bureau of Statistics' Socioeconomic Indices for Areas (SEIFA) measures.

This research was conducted in collaboration with [named government agency]. The main project had broad aims of examining factors enhancing social cohesion in multicultural contexts, and factors that militate against it, including points of stress between groups, with the two locations as case studies. The research was guided by the following key questions: What are individuals, community-based organisations, local government, policy makers, and businesses doing well in terms of 'getting along' in a multicultural/ethnically diverse environment? Where and what are the problems that affect social cohesion? Are there groups of people in particular difficulty? Are there current, emerging or foreseeable tensions between different people in Shepparton and Mildura? And what might be done about them?

The methodological approach was qualitative and interpretive. Background research included extensive literature review, examination of community surveys (including research on social capital and key social indicators in Shepparton and Mildura), and local government and local agency policy documents and other reporting, such as issues papers produced by local ethnic councils. We made twenty research fieldtrips (each 2-4 days), eleven to Shepparton and nine to Mildura in 2015. Key informants were selected in collaboration with our government agency research partners, and others were found through snowballing from interviews and focus groups, also from informal discussions with locals during fieldtrips. We conducted 78 semi-structured audio-recorded interviews with people in government and non-government agencies and organisations, local businesses, and in the general community, each between one- and two-hours duration. We interviewed or spoke to people from a wide range of organisations, including Victoria Police, Victorian Government agencies, local councils (including councillors, and council officers/managers), ethnic councils (CEOs/Managers, workers, volunteers), ethnic associations/societies, an Interfaith Network, Aboriginal organisations, welfare agencies, health agencies and services, universities and TAFEs, English Language Centres, the Adult Multicultural Education Service (AMES), local secondary and primary schools, local businesses, a sports club, churches, mosques and 
temples, philanthropic organisations, and service clubs. Among these 78 interviews, 34 people (15 in Shepparton; 19 in Mildura) were interviewed as community members rather than as stakeholders (though many had voluntary involvement in various relevant organisations), including people from Anglo, culturally and linguistically diverse (CALD), refugee, and Aboriginal backgrounds.

Semi-structured interviews included questions about agency work, focused on discussing key dimensions of social cohesion in multicultural environments. We conducted focus groups with Shepparton Police (10 officers), welfare workers in Mildura (12 people, including senior managers), and two groups of welfare volunteers/workers from CALD backgrounds, one in Mildura (4 people) and the other in Shepparton (3 people). For focus groups we encouraged general discussion of issues concerning social cohesion and multiculturalism, including discussions of how well people from different groups related with and experienced a sense of belonging in the communities. We also conducted observational research, including many informal discussions with local people on the street, in cafes and shops, and at social events where we observed interactions. We attended community meetings, cultural festivals and other events at both locations, recording observations as fieldnotes.

The analytic approach was interpretive. Transcribed data from interviews and focus groups was entered into software QSR NVivo, where it was coded both deductively and inductively. We began by searching for themes related to our research questions, and to Jenson's as well as The Scanlon Foundation's social cohesion dimensions of Belonging, Social justice and equity, Participation, Acceptance (and rejection), Legitimacy, and Worth (Markus and Dharmalingam 2007, p. 26). We also added emergent themes through an iterative approach, including identified problem areas for social cohesion. The fieldnotes recorded by both researchers were also analysed in a similar manner, but coding was done manually by hand, against text in notebooks.

The analysis was conducted collaboratively by the two researchers, who also co-conducted most of the interviews and all four focus groups. Informal analysis, including checking interpretations of data, began in the field, immediately after interviews and focus groups, in many conversations. Both researchers are male from white backgrounds and have endeavoured to be self-reflexive about how this shaped research encounters and interpretation. For example, this most likely resulted in people from non-white backgrounds sometimes playing down, or not elaborating upon, some of their experiences, for example of 
racial discrimination. Additionally, as many of the key agency people - the main focus of this article - were also from white (though ethnically diverse), middle-class backgrounds, this may also result in a down-playing of issues of racism and discrimination. The research was approved by our University Human Ethics Committee and was conducted with strict adherence to agreed ethical protocols, including maintaining anonymity of interviewees and other participants.

\section{Findings and discussion}

In the remainder of this article we discuss our findings, highlighting where they challenge and also where they support criticisms of social cohesion as a policy framework, as discourse, and as orienting the actions of local actors in rural communities. In particular, we address the meanings of community and understandings of social cohesion, confirming that 'harmony' is central to such meanings, and show that social conflict is seen as a threat rather than as socially productive. We also note how social cohesion discourse does engage with 'community governmentality' and is thus open to critiques that theorists have made of governmentality. However, we also show that adopting a general social cohesion framework does not prevent local agency workers from recognising structural barriers, or direct their attention away from racism, discrimination and entrenched disadvantage.

\section{Dominant meanings of social cohesion and community}

In our interviews and focus groups with representatives of non-government and government agencies, concepts such as social cohesion, social capital, community and multiculturalism were in everyday use. The CEO of an economic development agency in Mildura, for example, pointed to high levels of voluntarism among residents, as indicated in local council run community surveys, and explicitly mentioned these findings were part of a measurement of social cohesion, thus indicating a strong awareness of this dimension of social cohesion as argued for by theorists and policy makers. Most interviewees were used to speaking the language of social cohesion, and community was nearly always linked to social cohesion in these discussions. For most, social cohesion meant people living together in relative harmony and experiencing a sense of local community belonging and identity. This is close to the minimalist concept of social cohesion argued for by Chan et al. (2006: 289), which they explicitly based on the core, commonsense (dictionary) meaning of cohesion as 'to hold firmly together, form a whole'. Thus, when asked whether they felt that their towns were, in general, socially cohesive, interviewees typically referred to the extent to which different 
groups mixed together in the community, as well as the perceived absence of tension and conflict between groups (including racism and discrimination, and violence), and the extent to which people trusted each other and were prepared to work together for common goals.

For example, an interviewee (Government agency worker) said that Mildura had groups 'coexisting' rather than living cohesively. She explained that some groups, including some non-Aboriginal locals, Aboriginal people and more recent CALD immigrants, were marginalised. Similarly, a primary school principal, said firmly that Mildura was not socially cohesive, highlighting social class divisions and racism towards Aboriginal people. These and other interviewees were very conscious of inequalities. However, another interviewee, who thought Mildura was socially cohesive, emphasised the perceived lack of social conflicts between groups, compared with metropolitan cities:

I think you do have times where ... certainly communities maybe clash. It still happens here. I personally don't see a lot of it and I don't hear a lot about it here locally...not like you would see on the TV in Melbourne. They do see it a fair bit, but I think here it doesn't seem to be as bad (Manager for Labour hire firm, Mildura).

An interviewee who felt that Shepparton was a socially cohesive place, pointed to a perceived absence of public conflict between different groups of people in a multicultural environment, as evidence of social cohesion:

If you just walk down the lake on a Saturday night... during the summer months, it's social cohesion, multiculturalism.

Yeah, you just see all sorts of different people sharing a space?

Yeah, and there's no issues. There is some issues in the community, but you don't see it there. There's nothing major from our point (Police officer, Shepparton).

Thus, as per the critics of social cohesion as a discourse discussed earlier, there was among some interviewees an emphasis on overall harmony, and not much explicit recognition of the productiveness of conflict (Harris 2013). However, local discourses also involved positive affirmation of expression of different positions and cultures. In a focus group with police officers, the local superintendent spontaneously introduced a discussion of social capital and its importance to issues the police faced in policing a diverse town like Shepparton with large communities of recent immigrants from Iraq, Afghanistan, Sudan and South Sudan, and the Democratic Republic of the Congo. In this discussion he emphasised the importance of 
cultural differences and understanding and respecting peoples' differences, when policing and interacting with community members.

Here, the governmentality literature has critical purchase, stressing how discourses of social cohesion and community become embedded in thinking and practices of those on the frontline of actively trying to 'improve' community (Stead 2017), and thus, of 'selfgovernance' at the local, rural level. Stead views this phenomenon critically, emphasising how people from local agencies are complicit in conservative government approaches to managing, deemphasising and even ignoring local inequalities. In discussing social cohesion, community was a commonsense referent that everybody we interviewed used, and improving community, or strengthening community was an unquestioned aspiration. But as we argue below, this not only contained (for some) a conservative discourse about harmonious, value consensual rural community, but also contained, for many interviewees, more critical approaches to local social problems and issues. It also involved, as the above quotes show through the close tying together of social cohesion and visions of harmonious multicultural society, a commitment on the part of interviewees to find ways to improve intercultural interactions and understanding. When asked about what might be done to enhance social cohesion, an interviewee in Shepparton focused on closer engagement between the broader community and newer, international immigrant arrivals, but saw this also as involving structural issues:

Some of that social isolation is through poor English skills. It's also lack of access to transport, independence... Initiatives around integration seem to rest solely with the new arrivals. I don't know how you turn that around or what sort of programs you establish. But at history shows we haven't gone out of our way for previous communities. ... The settlement issues for these communities are much more complex because they are very visible communities. We've got to work out ways to be more inclusive across the mainstream community to try and actually get programs that engage these communities, rather than just provide them a service (Manager, multicultural organisation, Shepparton).

Many others emphasised the importance (and thus highlighting the current lack) of spaces and opportunities for meaningful, everyday cross-cultural interactions within their communities. In these accounts, it was clear that local understandings of social cohesion 
contained a stated desire to address various forms of marginalisation of minority community members and improve understanding across ethno-linguistic differences.

\section{Measuring community health as a form of governmentality}

In Shepparton and Mildura, representatives of agencies, including police and local government, think in terms of community as part of the solution to broader issues and problems such as population health, youth disengagement, crime, substance abuse, family violence and social dysfunction. The contradictory effects of governmentality in relation to community can be explored through the example of Mildura's 'Community Engagement Framework' (CEF), which involves the construction of community as a manageable, governed and governable object, but which at the same time mobilises agency workers around significant local social problems and is framed by social justice discourse.

In the early 2000s, Mildura Rural City Council began gathering extensive social indicators to measure the state of community health (Hawson 2013) - the kind of 'technical' approach to community that Rose (1996) argued was central to this form of governmentality. The inspiration and advice came from social researcher and advocate for social cohesion Tony Vinson, as several interviewees told us. As Silver (2010: 196) points out, the first Vinson Report, shaped by Catholic and Anglican conceptions of 'social cohesion', 'inspired Australian social inclusion discourse'. Notably, Mildura Rural City Council named one of its main social cohesion policies a 'Social Inclusion Policy', employed a 'social inclusion officer', and adopted a 'Social Inclusion Framework' with strong social justice dimensions aimed at CALD, Indigenous and disadvantaged communities (Mildura Rural City Council 2012). Vinson's social justice approach to social cohesion was evident in Mildura's politics of community, as evident in the CEF, which emphasised the multi-faceted and structural determinants of complex social disadvantage.

The CEF, which later merged with the Northern Mallee Primary Care Partnership to become the Northern Mallee Community Partnership, was a major social cohesion governing strategy (Mildura Rural City Council/Northern Mallee Community Partnership, 2013: 8). It was created in 2006, with a 'Governance Group' and several 'Operational Groups' drawing upon leaders in government and non-government sectors to engage with areas of concern highlighted by social indicators research. The Operational Groups engaged with the local community to address problems, issues and needs, some of which had been directed to them by the Governance Group, and also developed annual action plans in their particular area of 
concern. Many of the people we interviewed from key agencies were members of the CEF and later the Northern Mallee Community Partnership, attending meetings in one or more of the Operational Groups, and thus were closely engaged in this social cohesion strategy. An interviewee in Mildura spoke about the benefits of the CEF for policing, citing the example of a successful policing campaign to deal with the drug 'ice':

We saw an increase in the drug of ice ... We went to the Operational Group [part of the $\mathrm{CEF}$ ] and said, 'We think we've got a problem coming.' Now, because of the maturity of the Operational Group it was agreed straight away, because I'd done the rating on it that it was high levels of aggression, high levels of paranoia, higher levels of need for the drug. Immediately it was agreed, this is a wicked problem. Health came straight away, education came straight away and so we developed, 'Project Ice.' ... It wasn't left to the coppers to try to police their way out of it, it was something where all the agencies came together and said 'this has to be a shared problem'. As soon as we said, 'We've got a problem coming our way,' it was [already having] the trust and the understanding (Senior Police officer, Mildura).

The concern with community cannot simply be dismissed as a new form of oppressive governmentality. When thinking about a new form of 'governing through community' in rural towns such as Shepparton and Mildura, one needs to add to Rose's (1996) recognition that 'community' has been part of political thinking and discourse for a much longer time, a recognition of the particular valency that 'community' has in rural Australia. The idea of rural community as the repository of 'true community' has been evident in 'community studies' sociology that associated rural areas with gemeinschaft and cities with gesellschaft (Tönnies 1957; Newby 1980). Dempsey (1990), while critical of the binary logic that distinguishes community in city and rural Australia, nevertheless noted that there was a powerful sense of being a community - a consciousness of community - that had salient impact on how people thought and acted in the rural town he named 'Smalltown'. This consciousness also reflected the materiality of isolation, which meant people had to rely upon each other, and local community resources, in ways less evident in metropolitan cities. This phenomenon was especially true for Mildura, and many interviewees mentioned the importance of Mildura's isolation for the way community functioned. Wilding \& Nunn (2018) have also argued for the particular meanings of community, and the powerful ideology of community, in rural Australian towns. Thus, when people in Shepparton and Mildura spoke of their community, they drew not just upon technical understandings of community 
inspired by a new form of governmentality, but also upon a cultural repertoire with a much longer history. One striking instance of this is the way people in both towns drew upon their histories as communities of multi-ethnic immigration to support the idea of multiculturalism, and the successful integration of newer, diverse migrants, in the present. Thus, historical memory helped shape a contemporary view of the possibility of community inclusive of diversity, rather than older, more typical images of conservative, ethnically and culturally homogenous rural community.

Additionally, while people in Shepparton and Mildura often suggested that strengthening community could contribute to addressing social problems, they did not think that community alone could solve them. Even the CEF in Mildura was not described as simply being about increasing social bonds, rather, it was about the benefits of an active, organised community of local leaders, with networks throughout the wider community, being able to pool their resources and skills, and thinking together to come up with plans to deal with 'wicked' social problems. At the time of our study, the members of the CEF were meeting to adopt a 'collective impact' approach, as explained by one interviewee:

...[I]t's a more rigorous framework. It's... put a contextual thing around the more complex issues. I think this is a critical thing for communities. [If] you try and apply a simple solution to something that is very complex, chances are, you're going to have minimal impact. I think that's what we're finding. Domestic violence, drugs, alcohol in a community, levels of child disengagement, education. Anything in that space is, by and large, a complex community issue, that there's no linear response (Manager, Local Council, Mildura).

There was a recognition among many interviewees that some issues were shaped by larger social and economic policies requiring higher levels of government input and resource allocation. The social cohesion framework, and associated ideas of strengthening community, provided an impetus and an avenue for active local action, rather than simply hoping for solutions to be provided by distant governing bodies. The critiques of social cohesion discussed in the first section of this article, including governmentality critiques, also suggest that this approach diverts attention away from appreciating the impact of racism and discrimination, and of economic deprivation. In the next section we argue for further nuance to this claim. 


\section{Discussions of racism, discrimination and inequality, in the context of social cohesion 'talk'}

The interviews and discussions in this research were with people actively engaged in efforts to 'improve' their communities, particularly for recent immigrant and refugee groups, Aboriginal people, and a range of other disadvantaged groups (which included people experiencing economic disadvantage, intergenerational poverty, family violence and substance abuse). We had wide-ranging discussions about the general impact of racism and racial discrimination as problems they tried to address in their work. There was a mix of opinions, from those who felt that their communities were relatively free of racism and discrimination (though none denied its existence, or damaging nature, when it occurred), to those who felt that it was a deeper, widespread problem.

An interviewee, from a non-white background, argued that Shepparton's racism was deepseated and pervasive:

Shepparton is like stepping back in time. It's hidden. It's all very genteel but underneath it there is a very, very strong pattern of racism (Manager, Aboriginal organisation, Shepparton).

Several people discussed the damaging nature of hidden forms of racism and discrimination. The racism and discrimination experienced by Aboriginal people was frequently raised when people turned to discussions of social cohesion, and of social and economic marginalisation. Rates of Aboriginal unemployment were high in Shepparton (a key informant from an Aboriginal agency estimated that it hovered between 20 and 50 percent), and key informants from Aboriginal and non-Aboriginal backgrounds commented on this. It was notable to many people that, as one Aboriginal interviewee said,

You just don't see Aboriginal people serving in the main retail outlets (Education Officer, Shepparton).

Mildura had a more overt focus on Indigenous issues through proximity of the former Namatjira Aboriginal mission at Dareton and its extreme forms of disadvantage. When asked about how well multicultural Mildura had worked for its diverse populations, a local nonAboriginal leader and welfare advocate commented:

In a funny, ironic sort of a way I suppose it's the Indigenous part of the communities that in many areas are still alienated. My comments in relation to the Indigenous 
community is probably quite different to the other branches, if you like, of multiculturalism (CEO, Welfare organisation, Mildura).

An Aboriginal leader in Mildura gave a snapshot of the levels of Aboriginal disadvantage in the area:

Our housing, you look at the data, we tick all the wrong boxes for the wrong reasons. Whether it's health, whether it's justice. We had a meeting today. The Koori [e.g. Aboriginal] community, all the children in out of home care in this region, 40 percent of them are Koori. In child protection. 40 plus percent, we make up the community corrections dispositions here at Mildura. Justice system. Youth justice it's about 60 percent. When you start looking at the numbers, homelessness, employment rate, you get a picture (CEO, Aboriginal organisation, Mildura).

Welfare workers in Mildura, speaking in a focus group, referred to ways the Aboriginal community came together around suffering, for instance events such as funerals, rather than for more positive celebrations. Others, both Aboriginal and non-Aboriginal, and in both Shepparton and Mildura, spoke of the way historical and contemporary experiences of racism, mistreatment and rejection, resulted in different expectations about engaging in education and work, cycles of poverty difficult to break, and separation from the mainstream of Shepparton and Mildura.

Problems of persistent, inter-generational disadvantage were seen by many to threaten social cohesion, suggesting social cohesion discourse did not divert attention from the negative impacts of economic suffering. High levels of inequality threaten social cohesion (Maxwell, 1996), particularly levels of interpersonal trust (Green et al.: 18), and arguably contribute to higher levels of health and social problems, as discussed in the Australian and international literature (Habibis and Walter, 2009; Wilkinson and Pickett, 2010). Many of the interviewees explicitly or implicitly recognised this connection. There were sections of the population living in poverty that were disengaged from activities that interviewees described as part of the success of multicultural Shepparton and Mildura. This issue was especially highlighted when we spoke with representatives from community-based welfare agencies and representatives from government social services.

One government employee commented that Mildura had not found a way to encourage participation of marginalised people in multicultural and mainstream cultural and arts events. She spoke of a multicultural event she attended that seemed to attract a mainly middle-class 
demographic, with some participation from Mildura's diverse communities, but little or no participation from Mildura's low socio-economic communities:

It's a community where there's wonderful diversity and celebrations of that diversity, but it got me thinking. Where is the rest of our diverse community, and do they also respect, celebrate, value what we have?...Is it because they don't know about it? Is it because they don't value it, or is it other, more practical things like where certain events are held?...Even transport issues... and some of those communities are more marginalised, not just socially, economically, but also practically through the lack of transport infrastructure (Government agency manager, Mildura).

She also described the difficulty of getting parents out of their houses to participate in barbecues and picnics that her Department put on in parks in disadvantaged areas of Mildura. Parents would send the kids out to the event, and she would see them behind their closing doors, but they stayed away.

The coordinator at a community house in a poor, multi-ethnic area of Mildura also lamented the lack of active involvement of locals in the house's activities. He wondered if they had to think up different approaches to engage the most disadvantaged. Few participated, and he wondered about the purpose of the house and its well-established community garden. We heard similar comments from government social services and other welfare agencies in Shepparton - 'how do you engage people who are disengaged?' These practitioners' concerns with low participation demonstrates again the dual potential of social cohesion to be operationalised for conformity and for social justice. Their frustrations over 'disengagement' with agency services can be interpreted as a reflection of conformist expectations of 'good' citizenry. However, some of these accounts also portray a concern over peoples' inability to participate because of structural and cultural marginalisation.

One Shepparton interviewee commented he was shocked at the poverty he encountered when he moved to Shepparton after living in a more privileged city interstate. He had the feeling Shepparton had once been more prosperous, and that while people had resilience, the economic circumstances were now more difficult, saying:

It's really difficult to see people get a toehold here and make things work. There's lot of endeavour, but probably success is harder to find and to sustain' (CEO, nongovernment welfare agency, Shepparton). 
Another interviewee spoke of cycles of poverty that people from different backgrounds can lapse into:

I guess some of the main things in Shepparton I think are issues to do with poverty and that cycle of poverty and isolation. Those factors can impact ... the multicultural community. I guess a lot of new arrivals or people who have settled here, there are problems with employment and poverty within those communities. People come to Shepparton, for example, for the fruit-picking season, so they're coming with not a skilled background. Once the fruit season finishes, their employment choices are quite limited. I think employment and poverty have a big role to play in whether someone is able to fit into the community, whether they're able to engage in the community (Case worker, non-government welfare agency, Shepparton).

While adopting a broad social cohesion approach and set of discourses, interviewees also recognised the larger social forces that contributed to social disadvantage. In this respect, the critics of the social cohesion approach, who point to the conservative concepts of community underpinning it, and the 'depoliticisation of difference' (Stead, 2017: 15) that it encourages, perhaps overlook its conceptual basis of concern with equality and inclusion of diversity and underestimate the degree to which it can encourage stakeholders to focus on structural disadvantage, and provide them with a more critical political language of local agency.

\section{Conclusion}

Critiques of relevant policy and discourse are correct in their warnings that social cohesion has the potential to disguise and/or dismiss addressing systematic disadvantage and discrimination. However, as shown, it also has potential, as policy framework and discourse, to enable local stakeholders to act on behalf of their constituents toward fostering positive intercultural interactions and community. These same people invest a great deal of thought and emotional concern, engaging in creative problem solving when trying to address the impact of larger social and socio-economic inequalities. Most of the people we interviewed used social cohesion principles of inclusion, equality, and dignity to guide their actions and the programs they developed. Collaborative community initiatives, local historical narratives of rich cultural diversity, and opportunities to celebrate the multi-cultures represented in town, were some of the ways local stakeholders sought to strengthen the sense of belonging and respect for all diverse members of the community. 
We do not presume people who operate within social cohesion frameworks always pursue such aims, but the case studies of Shepparton and Mildura demonstrate how local stakeholders can conceptualise and operationalise social cohesion, oriented by key components as set out by academic researchers like Jane Jenson. It is important for academics to incorporate into their critiques a distinction between potentially homogenising discourses on the one hand and explicit tenets of the framework on the other. Even the notion of 'shared values' might be more or less homogenising depending on interpretation. Jenson argued that 'shared values' needed to be thought through carefully: which universally shared values were appropriate in the context of pluralist societies that exhibited value differences, and which values "can differ without threatening the capacity to engage in "developing a community"'? (Jenson, 1998: 3). Highlighting a point made in the Club of Rome's The Limits of Social Cohesion (Berger, 1998), Jenson emphasised an important distinction: that value differences were not in themselves a threat to social cohesion, rather 'it is how they are managed that counts' (Jenson, 1998: 17). The people on the ground, in communities, who work to 'manage' social cohesion are also concerned about social justice and injustice, and they are frustrated by the limitations they encounter in attempting to build community in the face of socio-economic and racial inequality. Policy that ignores structural inequality can perpetuate and exacerbate patterns of disadvantage and discrimination.

We do not seek to advance a functionalist argument in favour of social cohesion, rather to suggest that, despite its faults, people operate within its frameworks, in official and unofficial capacities, to build intercultural community, with some degree of recognition of structural inequalities. Given its faults, one perspective might be that social cohesion is a failed framework. Our research suggests it is better thought of as a flawed framework, one that people put to effective, if sometimes problematic, use. Beauvais and Jenson (2002: vii) argued that one way of assessing social cohesion as a framework is to consider its utility as a framing device for engaging constructively in social policy debate and conversation. For example, does it help policy activists to confront complex problems and to converse about the relationships between them? Does it help to establish policy goals? We would add: Does it enable local actors to engage and assist their communities to meet their varying needs? In the case of Shepparton and Mildura, the answer to each of these questions was, to a large extent, yes. Social cohesion has a dual nature. It has potential for homogenising diversity and masking inequality, coupled with potential to foster positive community building and intercultural interaction. This dual nature makes it vital to continue researching the impact of 
social cohesion in particular contexts, and to also continue contesting it, while avoiding the impulse to dismiss it outright.

\section{Acknowledegments}

This research was conducted in collaboration with [name of government agency] who provided key advice and assistance, including funding for the project. They have agreed to publication of this research in academic journals.

\section{References}

ABS (Australian Bureau of Statistics) (2017a) 2016 Census QuickStats (Statistical Area Level 3) Shepparton.

ABS (Australian Bureau of Statistics) (2017b) 2016 Census QuickStats (Statistical Area Level 3) Mildura.

Amin, A. (2005) 'Local Community on Trial', Economy and Society', 34 (4), 612-33.

Beauvais, C. \& Jenson, J. (2002) Social Cohesion: Updating the State of the Research, CPRN Discussion Paper No. F 22, Ottawa, Canadian Policy Research Networks, Inc.

Berger, P. (ed.) (1998) The Limits of Social Cohesion: Conflict and Mediation in Pluralist Societies. A report of the Bertelsmann Foundation to the Club of Rome, Westview, Boulder, $\mathrm{CO}$.

Bernard, P. (1999) Social Cohesion: A Critique, CPRN Discussion Paper No. F09, Ottawa, Canadian Policy Research Networks, Inc.

Bryson, L. \& Mowbray, M. (2005) 'More spray on solution: Community, social capital and evidence based policy', Australian Journal of Social Issues, 40 (1), 91-106.

Chan, J., To, H-P. \& Chan, E. (2006) 'Social Cohesion: Developing a Definition and Analytical Framework for Empirical Research', Social Indicators Research, 75 (2), 273-302.

Cheong, P., Edwards, R., Goulbourne, H. \& Solomos, J. (2007) 'Immigration, Social Cohesion and Social Capital: A Critical Review', Critical Social Policy, 27 (1), 24-49.

Cowden, S. \& Singh, G. (2017) 'Community Cohesion, Communitarianism and Neoliberalism', Critical Social Policy, 37 (2), 268-86. 
Dandy, J. \& Pe-Pua, R. (2013) Research into the Current and Emerging Drivers for Social Cohesion, Social Division and Conflict in Multicultural Australia. Report prepared for: Joint Commonwealth, State and Territory Research Advisory Committee (RAC). March 2013.

Dempsey, K. (1990) Smalltown: A Study of Social Inequality, Cohesion and Belonging, Melbourne, Oxford University Press.

Everingham, C. (2001) 'Reconstituting Community: Social Justice, Social Order and the Politics of Community', Australian Journal of Social Issues, 36 (2), 105-22.

Green, A., Janmaat, J. G. \& Han, C. (2009) Regimes of Social Cohesion, London, The Centre for Learning and Life Chances in Knowledge Economies and Societies.

Habibis, D. \& Walter, M. (2009) Social Inequality in Australia, South Melbourne, Oxford University Press.

Harris, A. (2013) Young People and Everyday Multiculturalism, New York, Routledge.

Hawson, M. (2013) 'The Advantage of Social Indicators in Strengthening Rural Communities: Lessons from Mildura, Victoria'. In S. Kinnear, K. Charters \& P. Vitartas (eds) Regional Advantage and Innovation, Heidelberg, Physica-Verlag.

Jaffe, J. (2006) 'Social Cohesion, Neoliberalism, and the Entrepreneurial Community in Rural Saskatchewan', American Behavioural Scientist, 50 (2), 206-25.

Jeannotte, M. S., Stanley, D., Pendakur, B., Jamieson, B., Williams, M. \& Aizlewood, A. (2002) Buying in or Dropping Out: The Public Policy Implications of Social Cohesion Research. Prepared for the Department of Canadian Heritage, Strategic Planning and Policy Coordination, Strategic Research and Analysis Directorate.

Jenson, J (1998) Mapping Social Cohesion: The State of Canadian Research. CPRN Study No. F/03. Ottawa: Canadian Policy Research Networks Inc./Renouf Publishing.

Joppke, C. (2004) 'The Retreat of Multiculturalism in the Liberal State: Theory and Policy', The British Journal of Sociology, 55 (2), 237-57.

McGhee, D. (2003) 'Moving to “our” common ground - a critical examination of community cohesion discourse in twenty-first century Britain', The Sociological Review, 51 (3), 376-404. Markus, A. \& Dharmalingam, A. (2007) Mapping Social Cohesion, The 2007 Scanlon Foundation Surveys, Clayton, Vic., Monash Institute for Global Movements. 
Maxwell, J. (1996) Social Dimensions of Economic Growth. The Eric John Hanson Memorial Lecture Series Vol VIII, January 25, 1996 Edmonton, Alberta, Department of Economics, University of Alberta.

Mildura Rural City Council 2012, Cultural Diversity and Inclusion Strategy 2012 to 2017, Mildura Rural City Council, Mildura.

Mildura Rural City Council /Northern Mallee Community Partnership (2013) Community Health and Wellbeing Plan, 2013-2017.

Newby, H. (1980) Community, Milton Keynes, UK, Open University Press.

Novy, A., Coimbra Swiatek, D. \& Moulaert, F. (2012) 'Social Cohesion: A Conceptual and Political Elucidation', Urban Studies, 49 (9), 1873-89.

Rose, N. (1996) 'The Death of the Social? Re-figuring the Territory of Government', Economy and Society, 25 (3), 327-56.

Silver, H. (2010) 'Understanding Social Inclusion and Its Meaning for Australia', Australian Journal of Social Issues, 45 (2), 183-211.

Stead, V. (2017) 'Doing "social cohesion": Cultural policy and practice in outer metropolitan Melbourne', Critical Social Policy, 37 (3), 1-20.

Tönnies, F. (1957 [1897]) Community and Society, translated and edited by C Loomis, New York, Harper and Row.

Vertovec, S. \& Wessendorf, S. (eds) (2010) The Multiculturalism Backlash: European Discourses, Policies and Practices, Hoboken, Taylor and Francis.

Wilding, R. \& Nunn, C. (2018) 'Non-metropolitan productions of multiculturalism: refugee settlement in rural Australia', Ethnic and Racial Studies, 41 (14), 2542-60.

Wilkinson, R. \& Pickett, K. (2010) The Spirit Level: Why Greater Equality Makes Societies Stronger, New York, Bloomsbury Press.

Author (2017)

Authors (2015) 


\section{University Library}

\section{- M M I N E R VA A gateway to Melbourne's research publications}

Minerva Access is the Institutional Repository of The University of Melbourne

Author/s:

Moran, A;Mallman, M

Title:

Social cohesion in rural Australia: Framework for conformity or social justice?

Date:

2019-06-01

Citation:

Moran, A. \& Mallman, M. (2019). Social cohesion in rural Australia: Framework for conformity or social justice?. AUSTRALIAN JOURNAL OF SOCIAL ISSUES, 54 (2), pp.191-206. https:// doi.org/10.1002/ajs4.65.

Persistent Link:

http://hdl.handle.net/11343/286862 